\title{
THE IMPACT OF HEAVY WORK INVESTMENT ON THE ECONOMY AND THE INDIVIDUAL
}

\author{
Simona Roxana Pătărlăgeanu ${ }^{1 *}$, Carmen Valentina Rădulescu ${ }^{2}$, Mihai Dinu ${ }^{3}$ \\ and Marius Constantin ${ }^{4}$ \\ 1)2314) Bucharest University of Economic Studies, Romania
}

\author{
Please cite this article as: \\ Pătărlăgeanu, S.R., Rădulescu, C.V., Dinu, M. and \\ Constantin, M., 2020. The Impact of Heavy Work \\ Investment on the Economy and the Individual. \\ Amfiteatru Economic, 22(Special Issue No. 14), \\ pp. $1085-1102$
}

\section{Article History}

Received: 30 June 2020

Revised: 22 August 2020

Accepted: 30 September 2020

DOI: $10.24818 / \mathrm{EA} / 2020 / \mathrm{S} 14 / 1085$

\begin{abstract}
Heavy work investment represents a research area which has been intensively debated in the specialised literature, especially since 2013. On the one hand, heavy work investment can be made in the means of production, in order to increase work productivity. On the other hand, it is correlated with numerous other factors related to the quality of life and the quality of work conditions, among which: the relationship between work - living standard personal life; workaholism and technology; the decision to retire and so on.

The objectives of this research are to identify the correlations between the quality of life and heavy work investment, as well as to assess the social and economic progress from the view point of the need for heavy work investment.

The research methods used in the study were mainly of a quantitative nature: bibliometric and econometric analysis (linear regression with cross-section data). The data used in the econometric models constructed were taken over from two sources: Eurostat and the World Bank.

The research findings highlight the fact that in the analysed European states, making work investments by increasing the work volume is not a justified measure, because its effects do not reflect directly on the social and economic progress, quantified as the nominal gross domestic product.
\end{abstract}

Keywords: heavy work investment, time as a resource, nominal gross domestic product, life expectancy at birth, knowledge society.

JEL Classification: C31, J0, I3.

* Corresponding author, Simona Roxana Pătărlăgeanu - e-mail: rpatarlageanu@eam.ase.ro 


\section{Introduction}

The economic activity is always stimulated through investments, which are the primary vector in the social and economic development strategies. The postindustrial society can quantify social and economic progress using macroeconomic indicators such as the nominal GDP, but the focus has now moved on the indicators which reflect the quality of life (Gujuman, 2018).

Technical progress is one of the factors leading to economic growth. In the information economy, the individual is his/her own force of production, generating creative work. The latter represents the main source of economic growth and technical progress, therefore the knowledge society is marked by vectors such as information, creativity, technology and time as a resource (Popescu and Popescu, 2018). These vectors determine how the investment policies change and involve acceptance of the theory according to which heavy investment in work and in the human capital (work conditions offered, personal time respected) leads to an increase in productivity and ensures a higher quality of life. Managing the balance between personal time and working time proves to be a process with significant social and economic implications for the individual and for businesses, within the context of heavy work investment .

Time as a resource is much more appreciated in crisis situations than in moments which are considered normal. The value allocated to the time resource varies depending on each individual, organisation or state. In spite of this, the medical, social, economic and technical crisis produced by the effects of the new coronavirus starting with the beginning of 2020 has contributed to reassessing the value of time as a resource, especially from the management view point (Gong et al., 2020).

The economic and social instability and uncertainty trigerred by the new coronavirus are exerting pressure on the manner in which people manage the crisis situations they are faced with. Each individual's social and professional responsibility in such crisis situations differs depending on the culture of each society (Karabag, 2020). However, crisis situations have as an effect the recalibration of the personal values and the careful assessment of resources, time included. With the high level of digitalisation of work trigerred by the new coronavirus (Chiolero, 2020) and the social distancing rules, there is the risk that the time spent working would increase, without any economic reward for the citizens who are now working more than before the crisis. Eventually, the employees who can adapt to such situations obtain the same benefits as during normal times, although the effort they are making is higher during the crisis.

The motivation to carry out this study derived from the impact of the transition to the information society on the economic activities, on their results and on the qualitative and quantitative consumption of labour force. With time being an extremely valuable resource in the knowledge society (David and Foray, 2001), its efficient management at individual or organisational level is of scientific interest and continues to be a topical subject. Moreover, this paper presents a different approach, as it correlates this aspect with the opportunities that heavy investment in work and in the human resource create for the information economy. On the one hand, time is analysed from the macroeconomic perspective, starting from the effects of using this resource. On the other hand, time is analysed as each individual's most precious resource, which contributes to higher living standards, manifesting itself in different ways from one culture to another. 
The research has a twofold objective. The first research line involves a quantitative approach to assessing the social and economic progress, using a relevant macroeconomic indicator (the nominal GDP), from the perspective of the need for heavy work investment. Thus, the first objective is to quantify the impact of the average number of usual weekly hours of work in the main job on the nominal GDP in European countries. The second line of research is also of a quantitative nature, but it focuses more on the individual welfare, which means that the research deals with social aspects. Consequently, the second research objective is to quantify the influence of the two indicators - the average number of usual weekly hours of work in main job and the share of the total population considered to be in good health - on another indicator, namely life expectancy at birth. The share of the population perceived to be in good health is one of the important indicators of sustainable development in the European Union. This indicator is meant to monitor the progress of the Member States in terms of the welfare of the population (Firoiu et al., 2020).

The novelty of this study stems from the quantitative approach used to deal with the topic of heavy work investment, translated into an increase in the volume of work, as well as from the correlation with the results obtained by European countries in terms of social and economic sustainable development.

The contents of the study are structured into sections: the introduction is followed by the first part of the research, the literature review. After having established the current state of knowledge in the field of heavy work investment, there follows the second part of the research, where the methodology used is explained. In the third part, the results of the research and the social and economic implications of heavy work investment are presented and explained. Finally, the fourth section offers an overview of the conclusions and limitations of this study, as well as suggestions for possible further research in this field.

\section{Literature review}

Regarding reviewing the specialised literature, we carried out an investigation aimed to identify, consult and quantify the scientific publications. On the other hand, we considered a bibliometric approach in order to have a scientific basis when dealing with the topic we are trying to bring our contribution to.

Heavy work investment in general and its social and economic implications in particular have been extensively debated over the last years in the specialised literature (Harpaz and Snir, 2014; Baumgartner et al., 2015; Kleemann and Thiele, 2015; Ali, Deininger and Harris, 2017; Rabenu et al., 2019), especially considering that globalization has reached a point in its development where the international dispersion of economic activities is reaching its peak (Postelnicu, Dinu and Dabija, 2015). Countries are facing multidimensional challenges regarding the transition from a linear economy model towards a new one (Dinu, 2019).

These published studies differ in terms of approach, most of them referring to effective investment in the means of production with a view to increasing work productivity. Most studies regarding the implications that these investments have on the various economic sectors were carried out in agriculture and they are quite contested. While some researchers see their potential for job creation (Baumgartner et al., 2015; Kleemann and Thiele, 2015), others fear that rural inhabitants whose occupation is farming will be losing their means of existence ( $\mathrm{Li}, 2011)$. Within the context of globalisation, foreign investments in the rural 
areas may have a negative effect on the rural economy, food security and safety to a certain extent (Chiripuci, Todirică and Toderaşc, 2018).

A recent and very topical approach of international researchers (Harpaz and Snir, 2014; Rabenu et al., 2019) is the study of work investment in correlation with numerous factors that influence it, among which: the balance between living standard-life, the personality factors which influence behaviour, intercultural similarities or differences, workaholism and addiction to technology, similarities between generations and even the decision to retire. There are numerous approaches to heavy work investment in the specialised literature and they deal both with the qualitative and the quantitative aspects. Most quantitative studies are carried out using descriptive and/or inductive statistical analysis.

Furthermore, the statistical analysis of the publications (therefore a bibliometric perspective) dealing with heavy work investment proves the scope of the scientific interest in this topic between 2013 and 2020. Quantified as the number of publications which tackle the topic of heavy work investment, the scientific interest has been growing throughout the analysed period. It is worth mentioning that $61.23 \%$ of the scientific documents produced between 1989-2020, in which the phrase "heavy work investment" is associated with the keywords, were indexed in the prestigious Web of Science data base between 2013-2010.

Regarding the 325 scientific documents published between 1989-2020, indexed in Web of Science and where the phrase "heavy work investment" is a part of the keywords, the bibliometric analysis indicates that various approaches were used to analyse the topic of heavy work investment: by establishing the correlation with the topic regarding the quality of life (because there are strong links between the following keywords: "heavy work investment" - stress, sleep quality, family, workaholism) and by relating to topics connected with the technical, economic and managerial performance (because there are strong correlations between the following keywords: "heavy work investment" performance, optimization, system, technology, management). The map of correlations among the keywords associated to the 325 previously mentioned scientific documents can be consulted in Appendix 1.

Therefore, the objectives of this research are in agreement with both above-mentioned approaches: pinpointing the correlation between the quality of life and heavy work investment and assessing the social and economic progress achieved due to the need for heavy work investment.

\section{Research methodology}

The main questions around which answers and proposals were formulated during this study are the following:

- To what extent is social and economic progress, quantified as a macroeconomic indicator, the nominal GDP, influenced by heavy work investment, manifested as an effort indicator, namely the average number of usual weekly hours of work in the main job?

- To what extent does heavy work investment manifested as an effort indicator, namely the average number of usual weekly hours of work in the main job and another indicator of sustainable development which measures the welfare of a country, namely the share of the population with a good state of health, influence the life expectancy at birth in European countries? 
The expected results of the research are that in the knowledge society heavy work investment focuses mostly on a more efficient allocation of work resources, including the employees' time resource. The decision an employer can make (or not make) to invest heavily in work is based, primarily, on factors which are of a technical nature (the employer must answer questions such as: Can work in the company be automated with the help of technology?), factors related to the human resource (Is it sustainable for the company to make a heavy work investment or is is better to run programmes meant to ensure the employees' lifelong learning?) or factors related to the environment in which the company operates, the legal and fiscal framework, the national and international political orientation.

The research hypotheses are the following:

- In European countries, at national level, heavy work investment in the form of increased work volume is not justified, because the effects of such a measure are not reflected in the social and economic progress, quantified as the nominal GDP.

- The welfare of the population quantified as the life expectancy at birth is higher in the European countries where the average number of usual weekly hours of work in the main job is low.

The research method used for this study is that of linear regression, a quantitative method, which is why the approach to the topic of heavy work investment is an econometric one. The type of linear regression used for this research is based on cross-section data, the indicators referring to the year 2018. An advantage of this approach is that the analysis focuses on a reality which is the closest to the present moment and highlights correlations among the effects of policies implemented over a longer period of time. The main limitation of this approach refers to the fact that the analysis does not encompass the historic effects of the studied phenomena (the time series are not included in the analysis). The cross-section data is characterised by multiple observations obtained at a certain moment (in our case the year 2018), referring to several entities (in this case the analysis refers to European countries), focusing on a single phenomenon (each indicator included in the study). The countries included in the analysis are the following: all the EU Member States in 2018, with the exception of Luxembourg, because its population is low when compared with that of any other European country included in this analysis. In this context, the analysis would not have been relevant if the indicators corresponding to Luxembourg had been included in this kind of quantitative research. On the other hand, two other European states were included in the analysis: Switzerland and Norway.

The research involved collecting and using several social and economic indicators. They were collected on March 8, 2020; from two sources: Eurostat and the World Bank, according to the explanations in table no. 1. 
Table no. 1. Indicators used in the research, classified by type and data source

\begin{tabular}{|c|l|c|c|}
\hline $\begin{array}{c}\text { Indicator } \\
\text { Abbreviation }\end{array}$ & \multicolumn{1}{|c|}{ Name of the Indicator } & Type of Variable & Data Source \\
\hline $\mathbf{I}_{1}$ & $\begin{array}{l}\text { The number of usual weekly } \\
\text { hours of work in main job }\end{array}$ & Independent & Eurostat \\
\hline $\mathbf{I}_{2}$ & $\begin{array}{l}\text { Share of total population }(\%) \\
\text { perceived to have a good or } \\
\text { very good state of health }\end{array}$ & Dependent & Eurostat \\
\hline $\mathbf{I}_{3}$ & Life expectancy at birth & Independent & Eurostat \\
\hline $\mathbf{I}_{4}$ & Nominal GDP & Dependent & The World Bank \\
\hline
\end{tabular}

Source: Own conceptualisation

As has been mentioned before, the values of the indicators collected correspond to the year 2018. In spite of this, in order to better capture the impact of the work volume and to make recommendations regarding the impact of heavy work investment on the quality of life and the macroeconomic results, the values of the indicator "average number of usual weekly hours of work in main job" were calculated as a median of the values of this indicator between 2000 and 2018. Thus, the research focuses on the effects of policies which are specific to the labour market. These policies were implemented and constantly adapted to the market needs for a long time, and the effects are analysed considering the social and economic realities of the year 2018 .

The objectives of this research required the construction of two econometric models, which facilitate studying the interconnections among variables (Anghelache, Petre and Olteanu, 2019). The first objective, namely quantifying the impact of the average number of usual weekly hours of work in main job on the nominal GDP in European countries will be reached by applying the simple regression method on the cross-section data. In this model, $i_{1}$ is the independent variable, while $i_{4}$ is the dependent variable, as can also be seen in table no. 1. As for the second research objective, it refers to quantifying the influence that two indicators, the average number of usual weekly hours of work in main job and the share of the total population whose state of health is perceived as good, have on another indicator, life expectancy at birth. Consequently, in the second econometric model, based on the cross-sectional multiple linear regression, $i_{1}$ and $i_{3}$ are the independent variables, while $\mathrm{i}_{2}$ is the dependent one.

The econometric models constructed for this research went systematically through the stages of specification, setting the parameters, testing and validation. This was achieved with the help of the EViews software, a tool used in quantitative research. Estimating the parameters in the cross-section linear regression was facilitated by the method of least squares. The main tests performed in the research were t-student (with the null hypothesis $\mathrm{H}_{0}$ : the coefficients do not differ significantly from 0 and the alternative hypothesis $\mathrm{H}_{1}$ : the coefficients are significantly different from 0), Durbin-Watson for testing the autocorrelation of test errors, Jarque-Bera to test if the errors of the model follow (or not) a normal distribution. Finally, the White test was used to verify the homoskedasticity or heteroskedasticity of the residuals of the constructed models. 


\section{Research findings and discussions}

The descriptive statistics analysis was carried out based on the statistical data in Appendix no. 5 and graphically illustrated in Appendix no. 2, 3 and 4. The descriptive statistics in table no. 2 allow one to highlight some characteristics of the analysed European countries from the perspective of the four indicators included in table no. 1.

Table no. 2. Descriptive statistics regarding the analysed indicators at European level (cross-section), reference year - 2018

\begin{tabular}{|c|c|c|c|c|}
\hline $\begin{array}{c}\text { Analysed Indicators and } \\
\text { Descriptive Statistics }\end{array}$ & $\mathbf{I}_{\mathbf{1}}$ & $\mathbf{I}_{\mathbf{2}}$ & $\mathbf{I}_{\mathbf{3}}$ & $\mathbf{I}_{\mathbf{4}}$ \\
\hline Unit of Measurement & Hours & Percentage & Years & USD \\
\hline Mean & 38.25 & 77.53 & 67.81 & $36,457.32$ \\
\hline Median & 38.83 & 79.10 & 70.60 & $30,098.28$ \\
\hline Maximum & 42.50 & 81.90 & 84.10 & $82,796.55$ \\
\hline Minimum & 30.75 & 70.10 & 44.00 & $9,272.62$ \\
\hline Standard Deviation & 2.60 & 3.63 & 10.11 & $21,174.45$ \\
\hline Skewness & -0.86 & -0.75 & -0.81 & 0.80 \\
\hline Kurtosis & 3.62 & 2.09 & 2.96 & 2.69 \\
\hline Jarque-Bera & 4.05 & 3.70 & 3.24 & 3.27 \\
\hline
\end{tabular}

Source: Own conceptualisation based on data from Eurostat and the World Bank

Thus, the descriptive statistics in table no. 2 confirm the following specificities of the 29 European countries included in the analysis:

- the standard deviation of the average life expectancy at birth in the case of the analysed countries is a bit over 10 years, which indicates discrepancies in terms of the quality of life in the analysed European states, from the perspective of this indicator - life expectancy at birth;

- referring to the nominal gross domestic product, the standard deviation is $\$ 21,174.45$ which justifies the fact that the analysed European countries are in different stages of economic development, the difference between the maximum value of $\$ 82,796.55$ and the minimum one of $\$ 9,272.62$ being $\$ 73,523.93$; $\$ 37,066.61$ above the average value (in the situation in which Luxembourg, with a GDP worth $\$ 116,639.888$; was excluded from the analysis because it would have distorted the linear regression results);

- similiar to the situation of the nominal GDP, for the the first indicator (average number of usual weekly hours of work in main job), the difference between the maximum value (42.5 hours) and the minimum one ( 30.75 hours) of this indicator is 4.51 times higher than the standard deviation. This indicates a discrepancy in terms of the average number of usual weekly hours of work in main job in the analysed countries. 

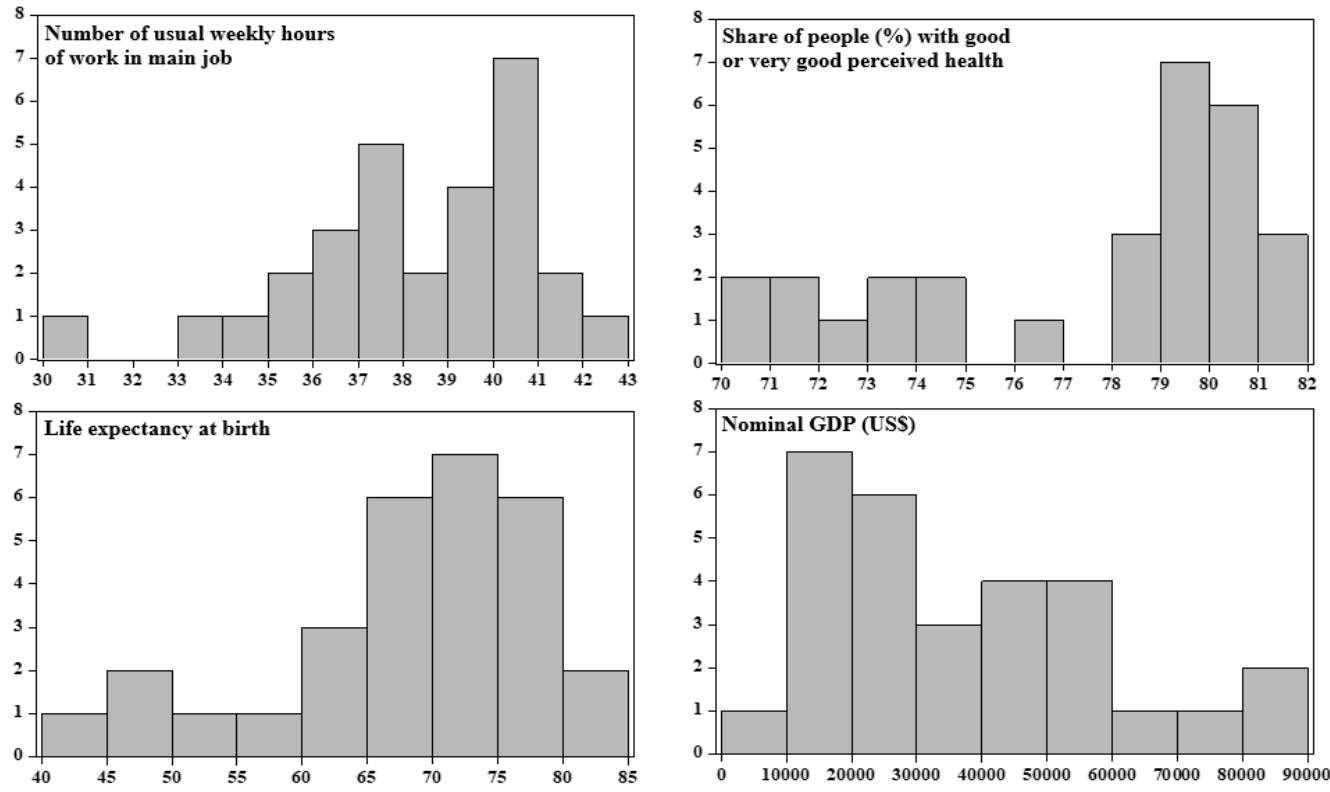

Figure no. 1. Distribution of the analysed series, at European level (cross-section), reference year 2018

Source: Own conceptualisation based on data from Eurostat and the World Bank

Moreover, figure no. 1 and the data in table no. 2 confirm the following:

- The analysed series do not have a normal distribution. Skewness is important because it reflects the asymmetric distribution of data around the median. In our particular case, one can notice the negative asymmetry (Skewness values below zero), except for the nominal GDP indicator, which displays positive asymmetry.

- Kurtosis is an indicator which reflects how flat or curved a distribution is compared to a normal one. In the case of a normally distributed series, the Kurtosis value is 3 (Startz, 2019). This criterion is not observed by the indicator "average number of usual weekly hours of work in main job" (leptokurtic series caused by the value above 3 ) and of the indicator "share of the total population with a state of health perceived as good (platikurtic series caused by the value below 3), while it is normal for the indicator "average life expectancy at birth" and almost normal for the "nominal GDP" indicator.

- The preponderantly normal distribution in the case of the previously analysed indicators for the year 2018 is caused by the different culture, level of development and results following the application of different social, economic and educational policies along time in the analysed European countries.

Starting from these first findings, the first econometric model constructed refers to the topic of heavy work investment, aiming to quantify the impact of the average number of usual weekly hours of work in the main job on the nominal GDP in European countries. Table no. 3 contains details regarding the formula of the method and of the equation, as well as the 
obtained coefficients and other relevant indicators which validate the designed econometric model.

Table no. 3. Parameters of the first econometric model and its equation

\begin{tabular}{|c|c|c|c|c|}
\hline \multicolumn{5}{|c|}{ Formula of the method used in EViews (least squares method - LS): } \\
\hline \multicolumn{5}{|l|}{$\mathrm{LS} \mathrm{I}_{4} \mathrm{C} \mathrm{I}_{1}$} \\
\hline \multicolumn{5}{|c|}{ Formula of the equation of the simple cross-section linear regression model: } \\
\hline \multicolumn{5}{|c|}{$\mathrm{I}_{4}=\mathrm{C}(1)+\mathrm{C}(2) \times \mathrm{I}_{1}+\varepsilon$} \\
\hline \multicolumn{5}{|c|}{ Equation of the model and coefficients obtained (the dependent variable is $I_{4}$ ): } \\
\hline \multicolumn{5}{|c|}{$\mathrm{I}_{4}=291,124.162271-6656.82054855 \times \mathrm{I}_{1}+\varepsilon$} \\
\hline Variable & Coefficient & Standard deviation & t-Statistic & Prob. \\
\hline $\mathbf{C}$ & $291,124.1623$ & $3,4365.7107$ & 8.4714 & 0.0000 \\
\hline $\mathbf{I}_{\mathbf{1}}$ & $-6,656.8205$ & 896.2906 & -7.4271 & 0.0000 \\
\hline
\end{tabular}

\begin{tabular}{|c|c|c|c|}
\hline $\mathbf{R}^{\mathbf{2}}$ & 0.671379 & Mean dependent var & $36,457.32$ \\
\hline Adjusted $\mathbf{R}^{\mathbf{2}}$ & 0.659208 & S.D. dependent var & $21,174.45$ \\
\hline S.E. of regression & $12,361.0942$ & Akaike info criterion & 21.748968 \\
\hline Sum squared resid & $4,125,509,523$ & Schwarz criterion & 21.843264 \\
\hline Log likelihood & -313.3600 & Hannan- Quinn criter. & 21.778500 \\
\hline F-statistic & 55.1615 & Durbin-Watson stat & 1.918177 \\
\hline Prob (F-statistic) & 0.0000 & \multicolumn{3}{|l}{} \\
\hline
\end{tabular}

Source: Own processing with the help of the EViews software

The t-student values of the parameters are calculated in the t-Statistic column. If Prob. $<0.05$, the null hypothesis is rejected: the parameters of the variables differ significantly from 0 . In this econometric model, the corresponding probability $\mathrm{I}_{1}$ is $<0.05$, so that the null hypothesis is rejected and the alternative hypothesis is accepted. The coefficients differ significantly from 0 , which validates the constructed model.

$\mathrm{R}^{2}$, the coefficient of determination, has acceptable values. In 2018, in the analysed European countries, the nominal GDP is explained in a proportion $67.13 \%$ by the exogenous variable (the average number of usual weekly hours of work in main job). In order to counter the mechanical increase of the coefficient of determination in case more variables were introduced in this econometric model, the Adjusted $\mathrm{R}^{2}$ indicator confirms its validity, due to the $65.92 \%$ which is similar to the coefficient of determination.

At the same time, the model passes the error autocorrection test, according to the DurbinWatson indicator. This indicator shows the correlation between the errors of the model and it should range around 2 so that the errors would not be correlated and that the model would be valid.

According to the simple, cross-section linear regression equation, with the coefficient of determination $67.13 \%$, in the case of the analysed European countries, one hour worked weekly in the main job triggers the diminishing of the nominal GDP by $\$ 6,656.82$; to which 
the free coefficient of $\$ 291,124.16$ is added. Thus, the model estimates that for 40 hours worked weekly in the main job, the nominal GDP of the European state where the respective individual is working will be $\$ 24,851.36$. If we increased the number of worked hours from 40 to 41 , there would be a negative effect on productivity, as reflected at macroeconomic level by the nominal GDP indicator, which would have the value of $\$ 18,194.54$ (down by $\$ 6,656.82$ ).

The testing of the model continued with the White test performed on the residuals of the linear regression model. The heteroskedastic character was noticed (errors do not have a constant dispersion), which was induced by the F-statistic 17.01 and Prob. F 0.0000 indicators - which is why remedial measures were taken in order to obtain the desirable residual homoskedasticity character. Thus, the residuals analysis revealed major deviations in the case of the Netherlands (the associated indicators had high deviations from the mean: for the number of usual weekly hours of work in main job, the difference from the mean was -7.5 hours, while the average deviation was of 2.6 hours, and for the nominal GDP the difference was of $\$ 16,566.68$ and the average deviation of $\$ 21,174.45)$. The particular case of the Netherlands demonstrates that heavy work investment by increasing the volume of work does not necessarily lead to social and economic progress, quantified by the nominal GDP macroeconomic indicator. Table no. 4 contains details regarding the formula of the method and the new model formula equation, when the Netherlands were excluded from the econometric model.

Table no. 4. Rectified parameters for the first econometric model and its equation (the Netherlands were excluded from the model)

\begin{tabular}{|c|c|c|c|c|}
\hline \multicolumn{5}{|c|}{ Formula of the method used in EViews (least squares method - LS): } \\
\hline \multicolumn{5}{|l|}{$\mathrm{LS} \mathrm{I}_{4} \mathrm{C} \mathrm{I}_{1}$} \\
\hline \multicolumn{5}{|c|}{ Formula of the equation of the cross-section simple linear regression model: } \\
\hline \multicolumn{5}{|c|}{$\mathrm{I}_{4}=\mathrm{C}(1)+\mathrm{C}(2) \times \mathrm{I}_{1}+\varepsilon$} \\
\hline \multicolumn{5}{|c|}{ Equation of the model and coefficients obtained (the dependent variable is $I_{4}$ ): } \\
\hline \multicolumn{5}{|c|}{$\mathrm{I}_{4}=368109.87104-8624.22642376 \times \mathrm{I}_{1}+\varepsilon$} \\
\hline Variable & Coefficient & Standard deviation & t-Statistic & Prob. \\
\hline $\mathbf{C}$ & $368,109.8710$ & $32,686.5153$ & 11.2618 & 0.0000 \\
\hline $\mathbf{I}_{1}$ & $-8,624.2264$ & 847.1168 & -10.1807 & 0.0000 \\
\hline
\end{tabular}

Source: Own processing with the help of the EViews software

In the case of the rectified model, the corresponding probability $I_{1}$ is $<0.05$, so that the null hypothesis is rejected and the alternative hypothesis is admitted. The coefficients are significantly different from 0 , which validated the constructed model. $\mathrm{R}^{2}$, the coefficient of determination, has high values. This time, the nominal GDP is explained in a proportion of $79.94 \%$ by the exogenous variable (the average number of usual weekly hours of work in main job) and the Adjusted $\mathrm{R}^{2}(79.17 \%)$ validates the rectified model. Also, the model passes the error autocorrection test, according to the Durbin-Watson indicator (2.22), since it is around 2, a situation which is favourable for the model. 
This time, the White test performed on the residuals of the rectified model confirms the desirable homoskedastic character (the errors have a constant dispersion), given by the F-statistic 1.38 and Prob. F 0.2691 indicators. The residuals mean is zero.

According to the equation of the new model, with a coefficient of determination of $79.17 \%$, for the European countries included in the analysis, one weekly hour of work in the main job triggers a drop in the nominal GDP by $\$ 8,624.22$, to which $\$ 368,109.87$ is added representing the free coefficient. Thus, the model estimates that for 40 hours worked weekly in the main job, the nominal GDP of the European state where the individual works will be $\$ 23,141.87$. In case of heavy work investment, if we were to increase the number of hours worked from 40 to 41 , the productivity would be affected in a negative way, this being reflected at macroeconomic level by the nominal GDP indicator, the value of which would be $\$ 14,517.65$ (down by $\$ 8,624.22$ ).

Although eliminating the Netherlands from the model has led to better results for the constructed econometric model (the coefficient of determination went up from $67.13 \%$ to $79.94 \%$ ), this only justifies the differences between the average of the analysed European countries and the Netherlands, which invests in the human capital looking at the quality of the work performed by the individual and not necessarily its quantity.

Lastly, heavy work investment has a direct quantitative and qualitative impact on the average number of usual weekly hours of work in the main job. The constructed econometric model confirms the first research hypothesis according to which, in the analysed European countries, heavy work investment in the form of increased work volume is not justified, because the effects of such a measure do not reflect upon the social and economic progress, quantified by the nominal GDP indicator. However, the investment in the human capital and in the quality of the hours worked represents a different approach to the quantitative one and may lead to better economic, social and professional results.

The second research objective is related to individual welfare, thus acquiring a stronger social character as compared to the first objective which focused mostly on the economic character. Consequently, this objective involves quantifying the influence of two indicators, the average number of usual weekly hours of work in the main job and the share of the total population with a state of health perceived as good, on another indicator, namely life expectancy at birth. Table no. 5 contains details regarding the second econometric model: the formula of the method and its equation, the coefficients corresponding to the variables, as well as other essential indicators which validate the constructed model.

Table no. 5. Parameters of the second econometric model and its equation Formula of the method used in EViews (least squares method - LS):

\section{$\mathrm{LS} \mathrm{I}_{2} \mathrm{C} \mathrm{I}_{1} \mathrm{I}_{3}$ \\ Formula of the cross-section simple linear regression model:}

\begin{tabular}{|c|c|c|c|c|}
\hline \multicolumn{5}{|c|}{$\mathrm{I}_{2}=\mathrm{C}(1)+\mathrm{C}(2) \times \mathrm{I}_{1}+\mathrm{C}(3) \times \mathrm{I}_{3}+\varepsilon$} \\
\hline $\mathrm{I}_{2}=77.6247$ & $37-0.40525$ & $692 \times \mathrm{I}_{1}+0.2272503$ & $1 \times \mathrm{I}_{3}+\varepsilon$ & \\
\hline Variable & Coefficient & Standard deviation & t-Statistic & Prob. \\
\hline $\mathbf{C}$ & 77.6247 & 8.7457 & 8.8756 & 0.0000 \\
\hline $\mathbf{I}_{1}$ & -0.4052 & 0.1818 & -2.2282 & 0.0347 \\
\hline $\mathbf{I}_{3}$ & 0.2272 & 0.0468 & 4.8490 & 0.0001 \\
\hline
\end{tabular}




\begin{tabular}{|c|c|c|c|}
\hline $\mathbf{R}^{\mathbf{2}}$ & 0.630465 & Mean dependent var & 77.531034 \\
\hline Adjusted R $\mathbf{R}^{\mathbf{2}}$ & 0.602039 & S.D. dependent var & 3.639869 \\
\hline S.E. of regression & 2.2962 & Akaike info criterion & 4.598068 \\
\hline Sum squared resid & 137.0835 & Schwarz criterion & 4.739512 \\
\hline Log likelihood & -63.6720 & Hannan-Quinn criter. & 4.642367 \\
\hline F-statistic & 22.1793 & Durbin-Watson stat & 1.720588 \\
\hline Prob(F-statistic) & 0.0000 & & \\
\hline
\end{tabular}

The $\mathrm{t}$-student values of the parameters are calculated in the t-Statistic column. For the second cross-section multiple linear regression model, the coefficients are significantly different from 0 , which validates the constructed model.

The coefficient of determination has acceptable values. In 2018, in the analysed European countries, the share of the population with a state of health perceived as good is explained in a proportion of $63.04 \%$ by the exogenous variables (the average number of usual weekly hours of work in main job and the average life expectancy at birth). In order to counter the mechanical increase of the coefficient of determination in case more variables were to be introduced in this econometric model, the Adjusted $\mathrm{R}^{2}$ indicator confirms its validity, since its value is $60.02 \%$, which is close to the coefficient of determination. The model also passed the error autocorrection tests, according to the Durbin-Watson indicator (1.72).

According to the cross-section multiple linear regression model in table no. 5, in $63.04 \%$ of the analysed European countries, if the average life expectancy at birth is 68 years (Table 1) and the average number of usual weekly hours of work in the main job is 38 hours, then the share of the total population with a state of health perceived as good is estimated to be $77.18 \%$. In case of heavy work investment, if we increased the number of worked hours from 38 to 42 and the other variable remained constant, this would affect the quality of life in a negative manner, which would reflect in the sustainable development indicator "share of the population with a state of health perceived as good", which would stand at $75.56 \%$ (down by 1.61 percentage points).

The testing of the model continued with the White test performed on the residuals of the multiple linear regression model. This test confirmed the desirable homoskedastic character (the errors have a constant dispersion) induced by the F-statistic 0.58 and Prob.F 0.7136 indicators. The median of the residuals is zero. Thus, the second research objective was reached and its corresponding hypothesis was confirmed. The welfare of the population, quantified by the life expectancy at birth is higher in the European countries where the number of usual weekly hours of work in the main job is low.

\section{Conclusions}

Heavy work investment stimulates the social and economic activity and represents one of the most important vectors of development, being important for decison makers from both the public and private sectors. In certain cases, the topic of heavy work investment is tackled mostly from the quantitative view point in order to assess the social and economic progress in correlation with the need for heavy work investment. In spite of this, there are approaches where work investment is analysed together with numerous factors related to 
the quality of life and the quality of working conditions, among which: the relationship between work - living standard - personal life; workaholism and technology; the decision to retire, and so on.

The objectives of this research have been reached. Heavy work investment has a direct quantitative and qualitative impact on the average number of usual weekly hours of work in the main job. The first econometric model constructed confirms the first research hypothesis according to which, in the analysed European countries, heavy work investment in the form of increased work volume is not justified, because the effects of such a measure do not reflect on the social and economic progress, quantified as the nominal gross domestic product. The second research hypothesis was also confirmed by ther second econometric model constructed: the welfare of the population, quantified as the life expectancy at birth is higher in the European countries where the average number of usual weekly hours of work in main job is low.

The novelty that this research brings to the topic of heavy work investment encompasses several aspects. In the first place, the novelty stems from the dual approach, which meant, on the one hand, explaining the relationship between heavy work investment and the social and economic progress (with a focus on the economic performance rather than on the implications for sustainable development or for the human factor, which has higher needs than the economic ones), and on the other hand it involved explaining the relationships between heavy work investment and the quality of life (with the accent on the correlations among the indicators of sustainable development and the heavy work investment indicator, in the form of the work volume, quantified as worked hours). In the second place, the novelty of this study is justified by the approach to the relationship between heavy work investment and the qualitative factors - work, the ratio between volume of work and personal life.

The main limitation of this study is represented by the cross-section character of the analysed data. The point of reference taken into account in this research is the year 2018, which is why any further research could focus on heavy work investment from the perspective of how the indicators evolved in time. Likewise, the research could also deal with other geographical locations besides Europe, or with the specific aspects related to heavy work investment in Romania.

Under the current conditions, when the whole society is affected by the COVID-19 pandemic, we consider that the indicator "share of the total population whose state of health is perceived as good", an indicator of sustainable development quantified at the level of the European Union, is becoming more and more relevant when the people with certain conditions (so-called morbidities) become the most vulnerable population in the case of the current and maybe also future pandemics. Therefore, it is imperative that effective measures should be taken by the governments which would lead to a better state of health of the whole population, considering that the economic crisis caused by a pandemic has more serious effects than the cost of preventing it. Thus, it is necessary to reassess the value of the time resource, especially from the view point of public and private management. 


\section{References}

Ali, D.A, Deininger, K. and Harris, A., 2017. Using national statistics to increase transparency of large land acquisition: evidence from Ethiopia. World Development, 93, pp.62-74.

Anghelache, C., Petre, A. and Olteanu, C., 2019. Unele concepte şi modele econometrice de analiză a performanţei macroeconomice. Revista Română de Statistică , Supliment, 4, pp.3-11.

Banca Mondială, 2020. GDP per capita (current US\$). [online] Available at: <https://data.worldbank.org/indicator/NY.GDP.PCAP.CD?view=chart> [Accessed at 8 March 2020].

Baumgartner, P., von Braun, J., Abebaw, D. and Müller, M., 2015. Impacts of Large-scale Land Investments on Income, Prices, and Employment: Empirical Analyses in Ethiopia. World Development, 72(C), pp.175-190.

Chiolero, A., 2020. Covid-19: a digital epidemic. BMJ, 368(764). doi.org/10.1136/ bmj.m764.

Chiripuci, B., Todirică, I. and Toderaşc, A., 2018. The Impact of Globalization Phenomena on Food Safety. In: Proceedings of the $1^{\text {st }}$ International Conference on Economics and Social Sciences. Challenges and Trends in Economic and Social Sciences Research. Bucharest, April 16-17, 2018. Bologna: Filodiritto Publisher. pp.21-27.

David, P. and Foray, D., 2001. An Introduction to the Economy of Knowledge Society. International Social Science Journal, 54(171), pp.9-23.

Dinu, V., 2019. The Transition to Bioeconomy. Amfiteatru Economic, 21(50), pp.5-7.

Eurostat, 2020a. Average number of usual weekly hours of work in main job - hours lfsa_ewhun2. [online] Available at <https://ec.europa.eu/eurostat/data/database> [Accessed 08 March 2020].

Eurostat, 2020b. Life expectancy at birth by sex TPSO0208. [online] Available at <https://ec.europa.eu/eurostat/data/database> [Accessed 08 March 2020].

Eurostat, 2020c. Share of people with good or very good perceived health by sex $S D G \_03 \_20$. [online] Available at <https://ec.europa.eu/eurostat/data/database> [Accessed 08 March 2020].

Firoiu, D., Ionescu, G.H., Băndoi, A., Florea, N.M. and Jianu, E., 2019. Achieving Sustainable Development Goals (SDG): Implementation of the 2030 Agenda in Romania. Sustainability, 11(7), 2156. doi.org/10.3390/su11072156.

Gong, B., Zhang, S., Yuan, L. and Chen, K.Z., 2020. A balance act: minimizing economic loss while controlling novel coronavirus pneumonia. Journal of Chinese Governance, 5(2), pp.1-20.

Gujuman, L., 2018. Impactul investitiilor asupra creșterii economice. In: 6th International Conference "Telecommunications, Electronics and Informatics". Chisinau, Moldova, May 24-27 2018. Chisinau: Technical University of Moldova. pp.24-27.

Harpaz, I. and Snir, R., 2014. Heavy Work Investment Its Nature, Sources, Outcomes, and Future Directions. Abingdon: Routledge/Taylor \& Francis Group. 
Karabag, S.F., 2020. An Unprecedented Global Crisis! The Global, Regional, National, Political, Economic and Commercial Impact of the Coronavirus Pandemic. Journal of Applied Economics and Business Research, 10(1), pp.1-6.

Kleemann, L. and Thiele, R., 2015. Rural welfare implications of large-scale land acquisitions in Africa: A theoretical framework. Economic Modelling, 51(C), pp.269-279.

Li, T.M., 2011. Centering labor in the land grab debate. The Journal of Peasant Studies, 38(2), pp.281-298.

Popescu, C.R.G. and Popescu, G.N., 2018. Methods of Evaluating "Intellectual Capital" of an Organization and Ways of Enhancing Performance in the Knowledge-based Economy - A Synthetically Approach. In: Vision 2020: Sustainable Economic Development and Application of Innovation Management. The $32^{\text {nd }}$ IBIMA Conference. Seville, Spain, 15-16 November 2018. Seville: IBIMA. pp.7060-7074.

Postelnicu, C., Dinu, V. and Dabija, D.C., 2015. Economic Deglobalization - From Hypothesis to Reality. E\&M Ekonomie a Management, 18(2), pp.4-14.

Rabenu, E., Shkoler, O., Lebron, M. and Tabak, F., 2019. Heavy-work investment, job engagement, managerial role, person-organization value congruence, and burnout: A moderated-mediation analysis in USA and Israel. Current Psychology, 38, pp.1-18. doi.org/10.1007/s12144-019-00423-6.

Startz, R., 2019. EViews Illustrated.. Santa Barbara, CA: University of California. 
Appendix no. 1. Correlations among the keywords in the 325 scientific publications (indexed in Web of Science between 1989-2020) on the topic of heavy work investment

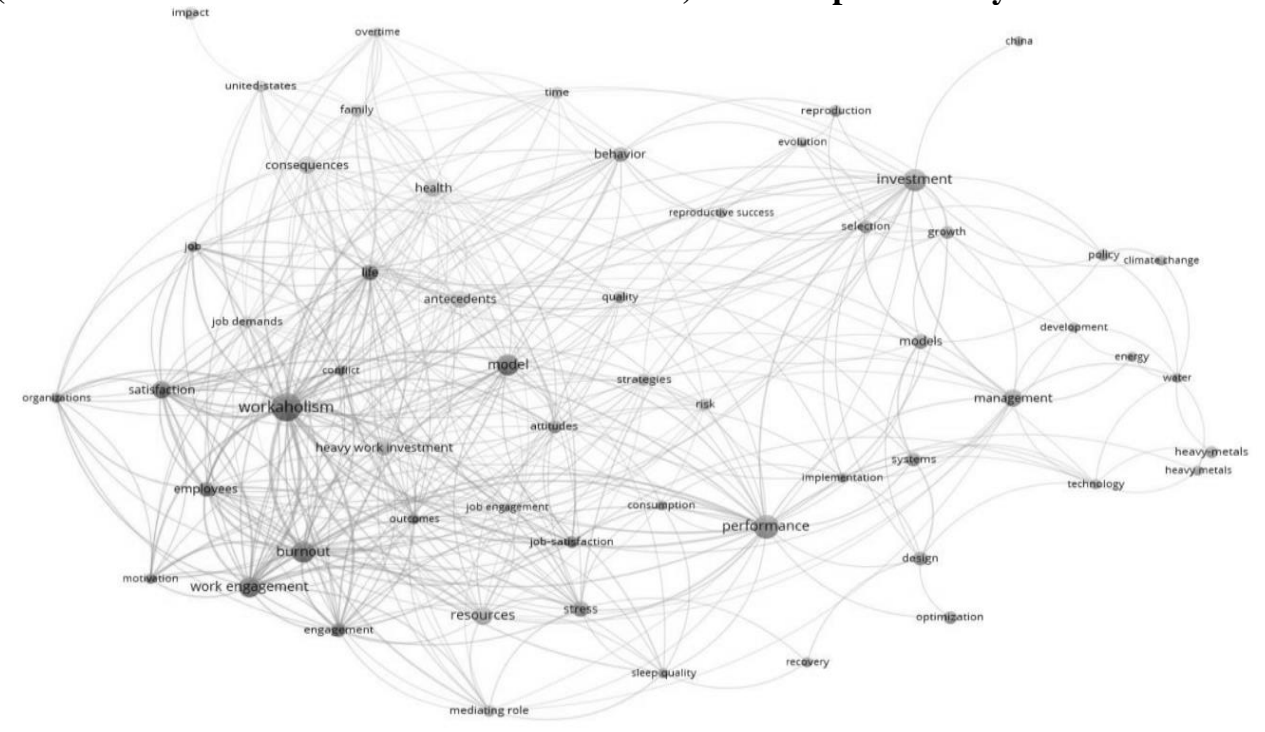

Source: Own conceptualisation in VOSviewer

Appendix no. 2. Average number of usual weekly hours of work in main job and the share of the total population with a state of health perceived as good in 2018 in the analysed European countries

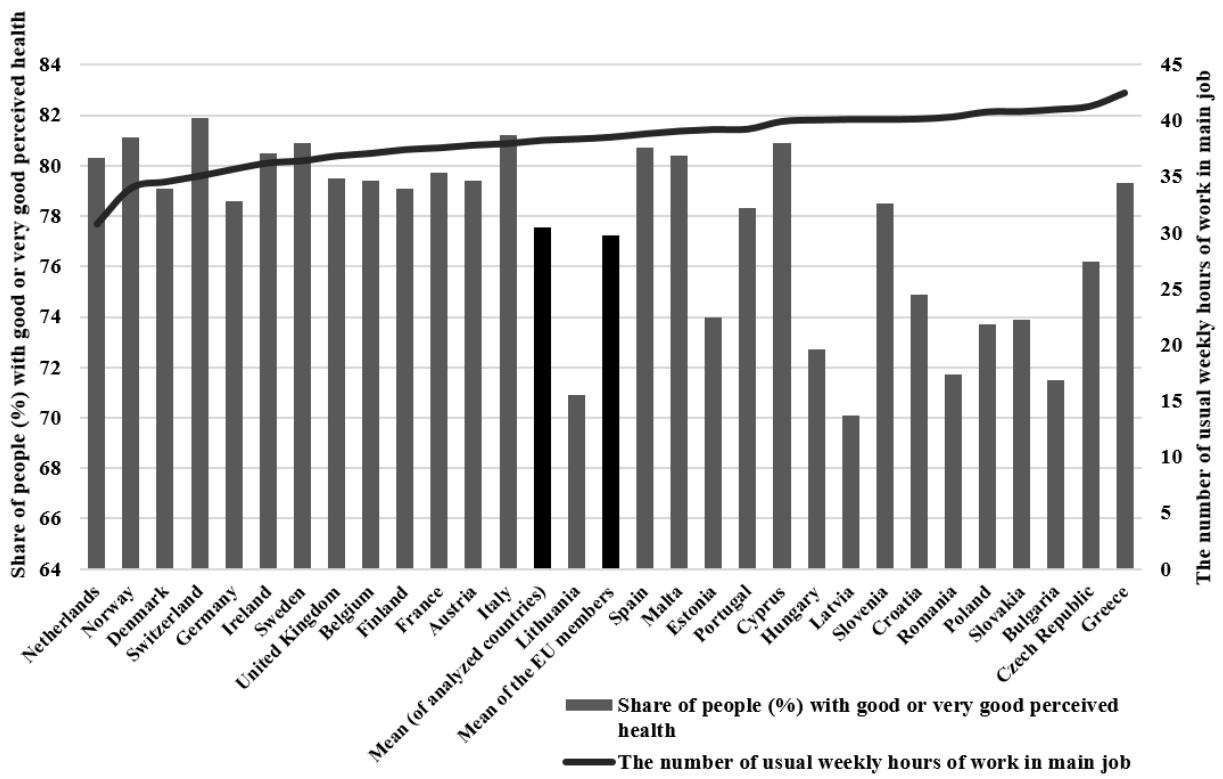

Source: Own conceptualisation based on Eurostat data

Appendix no. 3. Average number of usual weekly hours of work in the main job and the average life expectancy at birth in $\mathbf{2 0 1 8}$ in the analysed European countries 


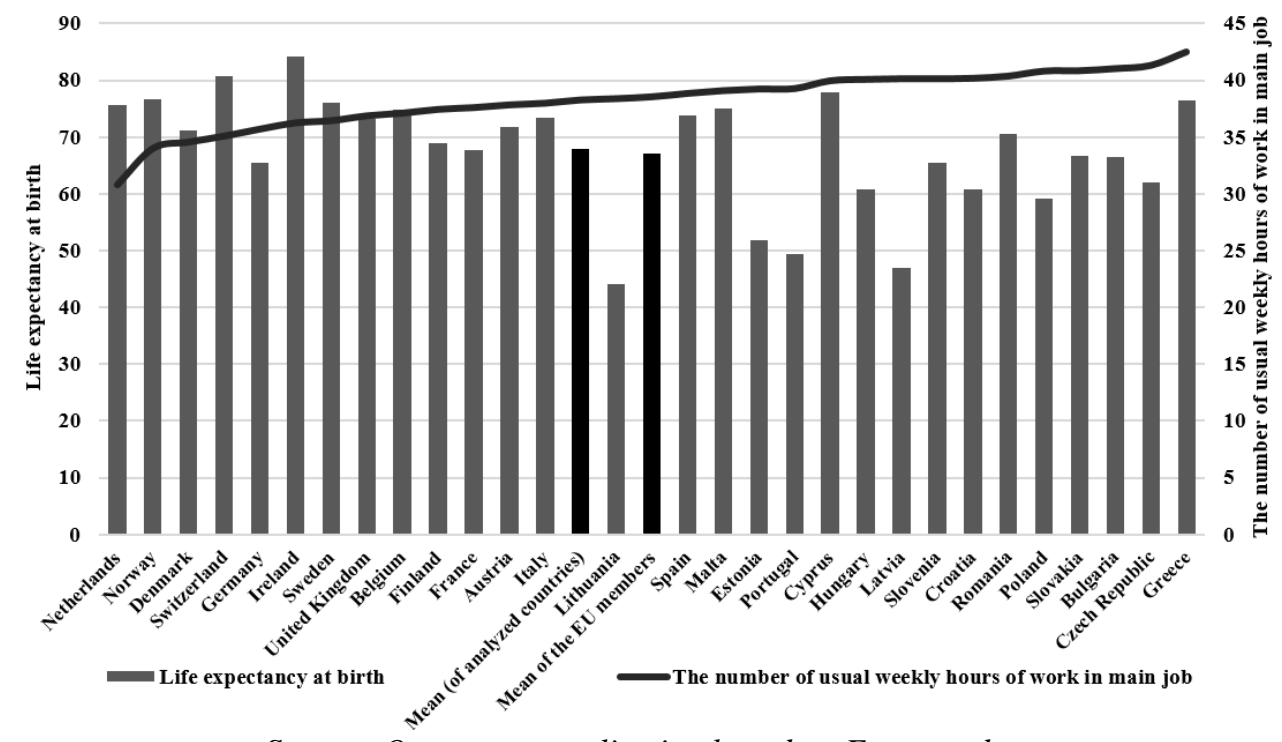

Source: Own conceptualisation based on Eurostat data

Appendix no. 4. Average number of usual weekly hours of work in main job and the nominal GDP in 2018 in the analysed European countries

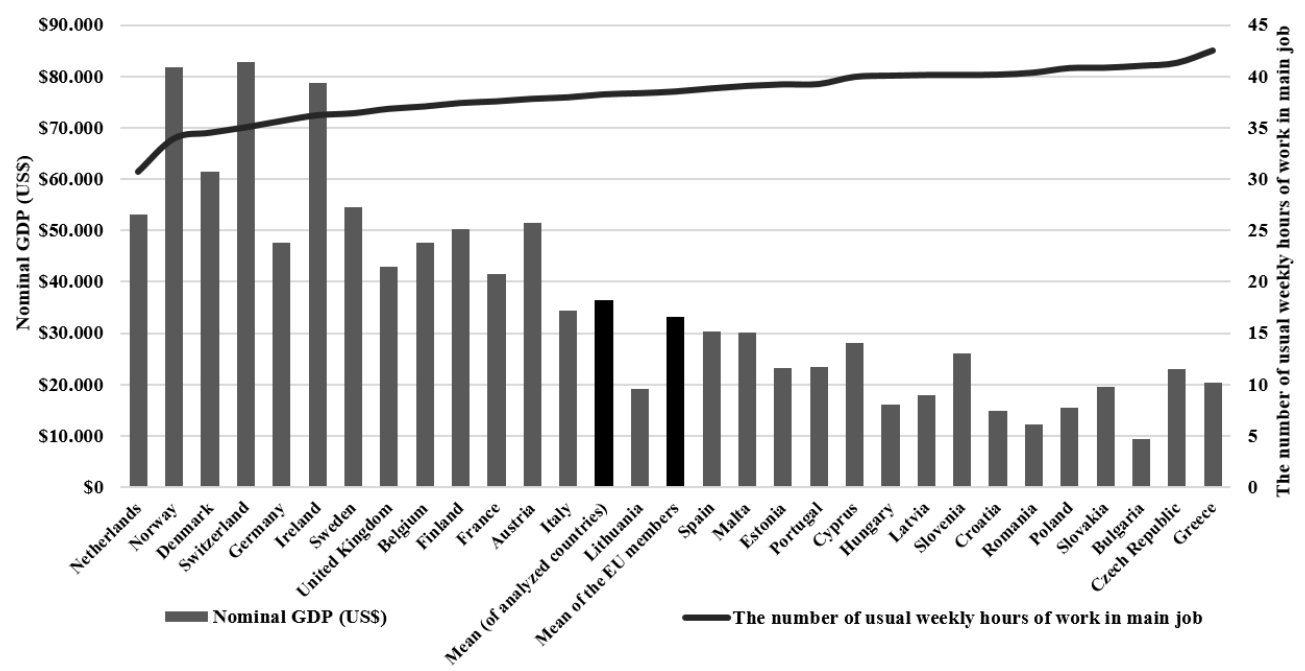

Source: Own conceptualisation based on Eurostat data

Note regarding the content of appendices 1, 2 and 3: the average of the indicators for the European Member States (identified in Figures 1,2 and 3 as "Average of EU Member States*") is calculated excluding the state of Luxembourg. 
Appendix no. 5. Values of the indicators used in the study for the reference year 2018

\begin{tabular}{|c|c|c|c|c|c|}
\hline No. & Country & $\begin{array}{l}\text { The number of } \\
\text { weekly hours } \\
\text { worked at the } \\
\text { main work place } \\
\text { (hours) }\end{array}$ & $\begin{array}{l}\text { Share of people } \\
\text { with a state of } \\
\text { health perceived } \\
\text { as good }(\%)\end{array}$ & $\begin{array}{l}\text { Life } \\
\text { expectancy } \\
\text { at birth } \\
\text { (years) }\end{array}$ & $\begin{array}{c}\text { Nominal } \\
\text { GDP } \\
\text { (USD) }\end{array}$ \\
\hline 1. & Greece & 42.51 & 79.3 & 76.4 & $\$ 20,324$ \\
\hline 2. & Czech Republic & 41.31 & 76.2 & 62.1 & $\$ 23,079$ \\
\hline 3. & Bulgaria & 41.03 & 71.5 & 66.5 & $\$ 9,273$ \\
\hline 4. & Slovakia & 40.84 & 73.9 & 66.7 & $\$ 19,443$ \\
\hline 5. & Poland & 40.81 & 73.7 & 59.2 & $\$ 15,421$ \\
\hline 6. & Romania & 40.36 & 71.7 & 70.6 & $\$ 12,301$ \\
\hline 7. & Croatia & 40.17 & 74.9 & 60.7 & $\$ 14,910$ \\
\hline 8. & Latvia & 40.13 & 70.1 & 47.0 & $\$ 17,861$ \\
\hline 9. & Slovenia & 40.13 & 78.5 & 65.4 & $\$ 26,124$ \\
\hline 10. & Hungary & 40.07 & 72.7 & 60.7 & $\$ 16,162$ \\
\hline 11. & Cyprus & 39.95 & 80.9 & 77.8 & $\$ 28,159$ \\
\hline 12. & Portugal & 39.26 & 78.3 & 49.3 & $\$ 23,408$ \\
\hline 13. & Estonia & 39.23 & 74 & 51.8 & $\$ 23,266$ \\
\hline 14. & Malta & 39.08 & 80.4 & 75.0 & $\$ 30,098$ \\
\hline 15. & Spain & 38.83 & 80.7 & 73.7 & $\$ 30,371$ \\
\hline 16. & Lithuania & 38.37 & 70.9 & 44.0 & $\$ 19,153$ \\
\hline 17. & Italy & 37.97 & 81.2 & 73.3 & $\$ 34,483$ \\
\hline 18. & Austria & 37.82 & 79.4 & 71.7 & $\$ 51,462$ \\
\hline 19. & France & 37.58 & 79.7 & 67.7 & $\$ 41,464$ \\
\hline 20. & Finland & 37.42 & 79.1 & 69.0 & $\$ 50,152$ \\
\hline 21. & Belgium & 37.08 & 79.4 & 74.8 & $\$ 47,519$ \\
\hline 22. & UK & 36.85 & 79.5 & 73.2 & $\$ 42,944$ \\
\hline 23. & Sweden & 36.42 & 80.9 & 76.1 & $\$ 54,608$ \\
\hline 24. & Ireland & 36.23 & 80.5 & 84.1 & $\$ 78,806$ \\
\hline 25. & Germany & 35.67 & 78.6 & 65.5 & $\$ 47,603$ \\
\hline 26. & Switzerland & 35.06 & 81.9 & 80.7 & $\$ 82,797$ \\
\hline 27. & Danmark & 34.53 & 79.1 & 71.2 & $\$ 61,350$ \\
\hline 28. & Norway & 33.97 & 81.1 & 76.6 & $\$ 81,697$ \\
\hline 29. & The Netherlands & 30.75 & 80.3 & 75.7 & $\$ 53,024$ \\
\hline
\end{tabular}

Source: Own conceptualisation based on Eurostat and World Bank data 